\title{
Publicações científicas em psicologia: a construção de um novo periódico
}

É com satisfação que apresentamos o primeiro número da revista do Departamento de Psicologia da Universidade de Santa Cruz do Sul- PSI UNISC. A revista surge como uma necessidade de interlocução entre os pesquisadores da UNISC e os demais pesquisadores da área em nível nacional e internacional.

A revista tem como meta a publicização da produção do conhecimento e de aprendizagens. Não se trata apenas de uma mera transmissão de saberes, mas um momento de diálogo, construção e reconstrução dos saberes e práticas individuais e coletivas. O trabalho científico nos desafia e nos instiga na descoberta de novas situações e nos impulsiona a diferentes formas de ação, a fim de pensarmos e apontarmos possibilidades de mudança. Portanto, o lançamento de um novo periódico científico é algo a ser celebrado, principalmente por ser mais uma contribuição dentre as diversas revistas na área da Psicologia. Busca também incentivar aqueles que se dedicam ao trabalho acadêmico, à prática profissional, veiculando experiências e pesquisas e ampliando espaços de publicação e difusão de saberes.

Nossa missão é promover o questionamento do conhecimento enquanto crítica e autocrítica, visando à construção de alternativas teóricas e práticas, em um diálogo que produza consensos, dissensos visando contribuir na transformação social. Portanto, "saber pensar e aprender a aprender correspondem ao compromisso de sair da mera cópia, para postar-se como capaz de construir conhecimento. E isto inclui, no mesmo processo, compreender e inovar a realidade". (Demo, 1994, p. 29).

Dessa forma, ao focalizar a amplitude da Psicologia, a revista PSI UNISC é um esforço dos professores do Departamento de Psicologia da UNISC de "tornar possível o que ainda não é possível", de forma a expandir as possibilidades de divulgar estudos em um novo espaço: "isso faz parte da tarefa histórica de redesenhar e reconstruir o mundo" (Freire, 1996).

Em seu primeiro número, a revista contém 12 artigos de seis estados e um artigo internacional. O primeiro artigo "O entorpecimento do trabalhador como estratégia de controle social no Brasil" de Alexandre João Appio e Nadir Lara Junior nos instiga a refletir sobre o entorpecimento do trabalhador pelo consumo de psicotrópicos como estratégia de controle social, problemática relevante na atualidade, sendo o Brasil um 
dos maiores consumidores de psicotrópicos. No segundo texto, contamos com uma colaboração internacional da pesquisadora Maria da Luz Cabral sobre "Longevidade: Cidadania, Participação e Direitos Sociais" que nos traz uma reflexão sobre o crescimento do número de pessoas com 65 anos ou mais, demonstrando um conjunto de políticas públicas e sociais, que nas últimas décadas foram implementadas em Portugal e que originaram a redução da mortalidade e consequentemente o aumento da longevidade naquele país. A próxima contribuição "Impactos da seca na saúde mental de moradores de uma comunidade rural" de Verônica Morais Ximenes e seu grupo de pesquisa analisa os impactos da seca na saúde mental de moradores da comunidade de Canafístula, no interior do Ceará. O quarto artigo "Atendimento psicológico domiciliar: relato de uma experiência" de Marta Maria de Lima Alexandre e Roberta Carvalho Romagnoli da PUC Minas discute uma das intervenções do psicólogo na atualidade apresentando a prática do atendimento domiciliar. O quinto texto de Adriano Schlosser e Gabriel Fernandes Camargo Rosa vai trabalhar com acadêmicos de Psicologia verificando suas representações sociais sobre a doença mental em artigo intitulado "Representações sociais de acadêmicos de psicologia acerca da loucura". O próximo texto investiga as narrativas sobre reflexões decorrentes da violência contra crianças e adolescentes, apresentado por Letícia Maísa Eichherr e Lílian Rodrigues da Cruz e intitula-se "Violência contra crianças e adolescentes: (in)visibilidades e problematizações". O sétimo estudo de Geraldine Alves dos Santos, uma pesquisa com delineamento descritivo, transversal e quantitativo avalia a Qualidade de vida de pessoas idosas praticantes e não praticantes de atividades físicas, revelando o quanto a atividade física contribui para a qualidade de vida em pessoas com mais idade. O oitavo texto "O Gestor Intermediário bancário e a Cultura do Management", escrito por Elisangela Carpenedo de Mattos e Álvaro Roberto Crespo Merlo, é parte de uma pesquisa qualitativa realizada com gestores intermediários, trabalhadores de um banco estatal, trazendo articulações entre saúde mental e trabalho. O próximo artigo de Mariana Yuki Kamada e Lilian Cristine Ribeiro Nascimento da UNICAMP intitulado "Educação e psicanálise: um estado do conhecimento" é resultado de uma pesquisa bibliográfica construído a partir da busca das palavras "educação e psicanálise" em dissertações e teses dos bancos de dados da Capes. O décimo trabalho apresentado: "Inclusão de alunos com necessidade de atendimento educacional especializado: Percepção dos professores" de um grupo de pesquisadoras do IMED objetivou conhecer a percepção dos professores sobre a inclusão de alunos deficientes em classe regular de ensino. O décimo primeiro texto "Reflexões acerca da formação em Gestalt-terapia no Brasil", escrito por Lázaro Castro Silva Nascimento e Jorge Ponciano Ribeiro descreve a história da formação em Gestalt-terapia no país. E, por último, apresentamos uma contribuição das autoras Juliana Rohde e Dulce Grasel Zacharias, "Estudo De Caso: Um Olhar Sistêmico para a Psicoterapia Individual" que é um entendimento sobre psicoterapia individual em um Serviço Escola. Portanto, todos esses estudos demonstram a relevância da revista em termos de propagação/inserção pelo território nacional, com textos de Brasília, Minas, São Paulo, Ceará, Santa Catarina e também de nosso estado o Rio Grande do Sul.

Neste sentido, a revista PSI UNISC surge como um periódico específico da área da Psicologia e suas articulações com outros campos do saber. Por essa razão, atribuímos o nome PSI UNISC. Ela nasce com o propósito de refletir, debater coletivamente a construção de conhecimento das comunidades acadêmicas, veiculando estudos, pesquisas e experiências científicas em periodicidade semestral. Todos os textos serão avaliados por um corpo de especialistas ad hoc, de maneira independente e 
anônima, em duplo cego. E todo o processo editorial será controlado e transparente, de modo que a PSI UNISC possa ser reconhecida como uma revista acadêmica de excelência.

Os editores da PSI UNISC convidam a toda comunidade científica a ler e divulgar a nossa revista e a enviar artigos para o próximo número a ser lançado em dezembro de 2017.

Dra. Silvia Virginia Coutinho Areosa

Docente do Departamento de Psicologia e do PPGDR UNISC

Dr. Jerto Cardoso da Silva

Docente do Departamento de Psicologia da UNISC

Dra. Cristiane Davina Redin Freitas

Docente do Departamento de Psicologia da UNISC

\section{Referências}

Demo, Pedro. (1994). Pesquisa e construção do conhecimento: metodologia científica no caminho de Habermas. Rio de Janeiro: Tempo Brasileiro.

Freire, Paulo. (1996). Pedagogia da Autonomia. $23^{\mathrm{a}}$ edição Paz e Terra. 